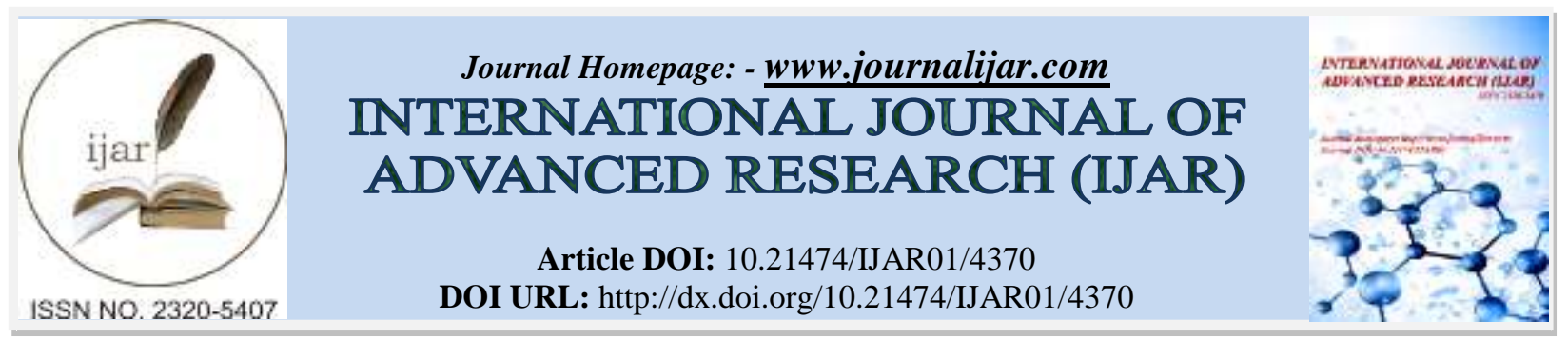

RESEARCH ARTICLE

\title{
COAGULATION PROFILE AS IMPORTANT MARKERS IN PREECLAMPSIA AND ECLAMPSIA
}

\author{
Dr Talat Fatma (M.D) ${ }^{1}$, Dr Shamim Khurrum Azmi (M.S) ${ }^{2}$, and Dr Ajit Kumar Chaudhary (M.D) ${ }^{3}$ \\ 1. Assistant Professor, Department of Pathology, Darbhanga Medical College, Darbhanga. \\ 2. Senior Resident, Department of surgery, Darbhanga Medical College, Darbhanga. \\ 3. Professor and H.O.D, Department of Pathology, Darbhanga Medical College, Darbhanga.
}

\section{Manuscript Info}

Manuscript History

Received: 18 March 2017

Final Accepted: 20 April 2017

Published: May 2017

\section{Keywords:}

preeclampsia, eclampsia, coagulation profile, markers

\section{Abstract}

Aim: To establish that coagulation profile is important marker and can be used to predict progression of preeclampsia and eclampsia.

Design: Retrospective study done at Darbhanga Medical College, Bihar from December 2003- January 2006.

Materials and methods:

140 pregnant women between $17 \mathrm{yrs}$ to $30 \mathrm{yrs}$ age were included in the study.

Among these women there were $41 \%(n=68)$ cases of preeclampsia, $23 \%(n=32)$ cases of eclampsia and remaining $29 \%(n=40)$ women with normal pregnancy in third trimester were taken as control.

$64.7 \%(\mathrm{n}=44)$ of preeclamptic women were $20 \mathrm{yrs}$ to $25 \mathrm{yrs}$ of age. $50 \%(n=16)$ women with eclampsia were 20-25 yrs of age.

Nulliparous women were higher in pre-eclamptic group (52.9\%) whereas only $25 \%$ of eclamptic women were nulliparous.

In this study group all patients except 4 were in third trimester of pregnancy, $47.1 \%$ of pre eclamptic group and $37.5 \%$ of eclamptic group were in early third trimester of pregnancy. Four eclamptic women $(12.5 \%)$ were in 25 weeks gestation.

The coagulation parameters tested were bleeding time, clotting time, prothrombin time, thrombin time, activated partial thromboplastin time, plasma fibrinogen, and platelet count.

The values of coagulation parameters were statistically analysed in preeclamptic, eclamptic and control group.

Results:

Bleeding time (B.T):

- Difference in mean value of preeclamptic $(2.45 \pm 0.48$ S.D. $)$ with that of normal $(2.3 \pm 0.19$ S.D.) difference was insignificant $(\mathrm{p}<0.1)$

- Difference in mean value of B.T. of eclamptic (2.94 \pm 0.47 S.D.)with that of normal (2.3 \pm 0.19 S.D. $)$ was significant $(\mathrm{p}<0.001)$

Clotting time (C.T.):

- Difference in mean value of C.T. of preeclamptic $(4.23 \pm 0.37$ S.D.) and normal (4.2 \pm O.37 S.D) was statistically insignificant $(\mathrm{p}<0.1)$. 
- $\quad$ Difference in mean value of C.T. of eclamptic (5.19 \pm 0.38 S.D.) and normal women (4.2 \pm O.37 S.D) was statistically significant $(\mathrm{p}<0.001)$.

Prothrombin time (P.T.):

- Difference in mean value of P.T. of preeclamptic $(0.96 \pm 0.05$ S.D.) and normal $(0.92 \pm 0.1$ S.D) was statistically insignificant $(\mathrm{p}<0.1)$.

- Difference in mean value of P.T. of eclamptic (1.09 \pm 0.13 S.D.) and normal women $(0.92 \pm 0.1$ S.D) was statistically significant $(\mathrm{p}<0.001)$.

Thrombin time (T.T):

- Difference in mean value of T.T. of preeclamptic $(0.99 \pm 0.13$ S.D.) and normal (0.86 \pm 0.09 S.D) was statistically significant $(\mathrm{p}<0.001)$.

- $\quad$ Difference in mean value of T.T. of eclamptic (1.09 \pm 0.2 S.D.) and normal women $(0.86 \pm 0.09$ S.D) was statistically significant $(\mathrm{p}<0.001)$.

Activated partial thromboplastin time (APTT):

- $\quad$ Difference in mean value of APTT of preeclamptic (49.96 \pm 8.72 S.D.) and normal (55.59 \pm 12.19 S.D) was statistically insignificant $(\mathrm{p}<0.1)$.

- $\quad$ Difference in mean value of APTT of eclamptic $(59.26 \pm 11.65$ S.D.) and normal women (55.59 \pm 12.19 S.D) was statistically insignificant $(\mathrm{p}<0.1)$.

Plasma fibrinogen:

- Difference in mean value of Plasma fibrinogen of preeclamptic (350.23 \pm 58.53 S.D.) and normal (492.17 \pm 82.73 S.D) was statistically significant $(\mathrm{p}<0.001)$.

- Difference in mean value of plasma fibrinogen of eclamptic $(227.50 \pm 57.45$ S.D.) and normal women (492.17 \pm 82.73 S.D) was statistically significant $(\mathrm{p}<0.001)$.

Platelet count:

- Difference in mean value of platelet count of preeclamptic (2 \pm 0.75 S.D.) and normal (2.43 \pm 0.26 S.D) was statistically significant $(\mathrm{p}<0.001)$.

- Difference in mean value of plasma fibrinogen of eclamptic (1.68 \pm 0.66 S.D.) and normal (2.43 \pm 0.26 S.D) was statistically significant $(\mathrm{p}<0.001)$.

Copy Right, IJAR, 2016,. All rights reserved.

\section{Introduction:-}

Preeclampsia and eclampsia are disorders of pregnancy characterized by high blood pressure and proteinuria. Preeclampsia is defined as hypertension that occurs in pregnancy for the first time after 20 weeks of gestation and disappears following delivery.

There are marked changes in the coagulation and fibrinolytic system occurs during normal pregnancy leading to hypercoagulable state. These changes are more magnified during eclampsia and preeclampsia. Coagulation activation probably represents a secondary event consequent upon endothelial activation and damage. Antithrombin which binds and inactivates thrombin correlates inversely with the level of proteinuria and subsequent renal dysfunction.

Early assessment of severity of pre-eclampsia and eclampsia is necessary to prevent complications like HELLP syndrome and increased maternal and fetal morbidity and mortality. These disorders are an important cause of severe morbidity, long-term disability and death among both mothers and their babies. 
Hence, this study was undertaken with the aim to compare the coagulation parameters of women with pre-eclampsia and eclampsia with normal women so as to identify the correlation of coagulation parameters with severity of preeclampsia and eclampsia.

\section{Material and Methods:-}

\section{Material:-}

140 pregnant women between $17 y$ yrs to 30 yrs age were included in the study. The women were selected from among those who presented in Darbhanga Medical College and Hospital for antenatal care and also those who presented in emergency with eclamptic fits.

\section{These women were Divided in three groups:-}

Normal pregnant control - 40 women

Preeclampsia $\quad-68$ women

Eclampsia $\quad-32$ women

Total -140 women

A detailed obstetric history including past and present history regarding associated medical disorders and bleeding diathesis was taken. In the physical examination blood pressure and presence or absence of edema was particularly taken note of.

In the control group healthy pregnant women of same age and gestation period were taken. Care was taken to rule out women with any underlying disease.

In this study the coagulation parameters studied were: bleeding time, clotting time, prothrombin time, thrombin time, activated partial thromboplastin time, plasma fibrinogen and platelet count. These tests were carried out in the Hematology lab under Department of Pathology, Darbhanga Medical College by using SYSMEX XS 3 part hematology analyzer and SYSMEX CA-500 series Coagulometer.

\section{Statistical Calculation:-}

The values of coagulation parameters was statistically analyzed by determining the mean, standard deviation (S.D), Standard Error of Mean (S.E.M), t value, p value. All statistical tests were 2 -sided and a $P<0.05$ was recognized as the statistically significant.

\section{Observation and Results:-}

The study group included 140 pregnant women between $17 y$ rs to 30 yrs age. Among these 68 women presents with preeclampsia, 32 women with eclampsia and 40 healthy pregnant women in third trimester of pregnancy were taken as control.

Table no 1:- Showing age distribution of study group.

\begin{tabular}{|l|l|l|l|l|}
\hline \multirow{2}{*}{ Age group in yrs } & \multicolumn{2}{|l|}{ Patients with preeclampsia(n=68) } & \multicolumn{2}{l|}{ Patients with eclampsia(n=32) } \\
\cline { 2 - 5 } & Number & Percentage & Number & Percentage \\
\hline $20-25$ & 44 & 64.7 & 16 & 50 \\
\hline $26-30$ & 24 & 35.3 & 12 & 37.5 \\
\hline$>30$ & 0 & 0 & 4 & 12.5 \\
\hline
\end{tabular}

Hence it was seen that majority of patients were between $20-30$ years.

Table no 2:- Distribution of cases according to parity

\begin{tabular}{|l|l|l|l|l|}
\hline \multirow{2}{*}{ Parity } & Patients with preeclampsia $(\mathbf{n}=68)$ & \multicolumn{3}{|l|}{ Patients with eclampsia(n=32) } \\
\cline { 2 - 5 } & Number & Percentage & Number & Percentage \\
\hline P0 & 36 & 52.9 & 8 & 25 \\
\hline P1 & 16 & 23.5 & 8 & 25 \\
\hline P2 & 8 & 11.8 & 16 & 50 \\
\hline P3 & 8 & 11.8 & 0 & 0 \\
\hline
\end{tabular}


Hence it was seen that majority of preeclamptic women were nulliparous $(52.9 \%)$ indicating higher incidence of pregnancy being complicated with preeclampsia in primigravida. This trend was not seen in eclamptic group where only $25 \%$ were primigravida.

Table no 3:- Distribution of cases according to gestation age

\begin{tabular}{|l|l|l|l|l|l|}
\hline \multirow{2}{*}{ Patient group } & \multicolumn{2}{|l|}{ Gestation age } & \multicolumn{2}{l}{ Total number } \\
& of cases \\
\cline { 2 - 5 } & Number & Percentage & Number & Percentage & \\
\hline Preeclamptic & $\mathbf{3 2}$ & $\mathbf{4 7}$ & $\mathbf{1 8}$ & $\mathbf{5 2 . 9}$ & $\mathbf{6 8}$ \\
\hline Eclamptic & $\mathbf{1 2}$ & $\mathbf{3 7 . 5}$ & $\mathbf{8}$ & $\mathbf{5 0}$ & 32 \\
\hline
\end{tabular}

In the study group all the patients except 4 were in the third trimester of pregnancy. $47 \%$ of preeclamptic and $37.5 \%$ of eclamptic women were in early third trimester of pregnancy. Four eclampsia cases (12.5\%) were in 24 weeks of gestation.

The coagulation parameters studies were:

1. Bleeding time (BT)

2. Clotting time $(\mathrm{CT})$

3. Prothrombin time (PT)

4. Thrombin time(TT)

5. Activated partial thromboplastin time( APTT)

6. Plasma fibrinogen

7. Platelet count

Bleeding Time $(\mathrm{Bt})$ :-

Table no 4a:- Bleeding time abnormalities.

\begin{tabular}{|c|c|c|c|c|}
\hline Patient group & No of cases & Range (minutes) & Mean BT & \pm SD \\
\hline Preeclamptic(A) & 68 & $2.0-3.4$ & 2.45 & 0.48 \\
\hline Eclamptic(B) & 32 & $2.3-3.6$ & 2.94 & 0.47 \\
\hline Control(C) & 40 & $2.0-2.5$ & 2.30 & 0.19 \\
\hline
\end{tabular}

Table no 4b:- Significance of difference from normal pregnant control

\begin{tabular}{|l|l|l|l|l|}
\hline & SEM & Z value & P value & Significance \\
\hline A vs. C & $\mathbf{0 . 0 9}$ & $\mathbf{1 . 5 8}$ & $<\mathbf{0 . 1}$ & Insignificant \\
\hline B vs. C & $\mathbf{0 . 1 2}$ & $\mathbf{3 . 9 2}$ & $<\mathbf{0 . 0 0 1}$ & Highly significant \\
\hline
\end{tabular}

- $\quad$ Difference in mean value of preeclamptic $(2.45 \pm 0.48$ S.D.) with that of normal (2.3 \pm 0.19 S.D. $)$ difference was insignificant $(\mathrm{p}<0.1)$

- $\quad$ Difference in mean value of B.T. of eclamptic $(2.94 \pm 0.47$ S.D.)with that of normal (2.3 \pm 0.19 S.D.) was significant $(\mathrm{p}<0.001)$

Clotting Time:-

Table no 5a:- Clotting time abnormalities

\begin{tabular}{|c|c|c|c|c|}
\hline Patient group & No of cases & Range (minutes) & Mean CT & \pm S.D \\
\hline Preeclamptic(A) & 68 & $4.0-5.2$ & 4.23 & 0.44 \\
\hline Eclamptic (B) & 32 & $4.5-5.6$ & 5.19 & 0.38 \\
\hline Control(C) & 40 & $3.5-4.5$ & 4.20 & 0.37 \\
\hline
\end{tabular}

Table no 5b:- Significance of difference from normal pregnant control.

\begin{tabular}{|l|l|l|l|l|}
\hline & SEM & Z value & P value & Significance \\
\hline A vs. C & 0.10 & 0.21 & $<0.1$ & Insignificant \\
\hline B vs. C & $\mathbf{0 . 1 2}$ & 7.87 & $<\mathbf{0 . 0 0 1}$ & $\begin{array}{l}\text { Highly } \\
\text { significant }\end{array}$ \\
\hline
\end{tabular}


- Difference in mean value of C.T. of preeclamptic (4.23 \pm 0.37 S.D.) and normal (4.2 \pm O.37 S.D) was statistically insignificant $(\mathrm{p}<0.1)$.

- Difference in mean value of C.T. of eclamptic (5.19 \pm 0.38 S.D.) and normal women (4.2 \pm O.37 S.D) was statistically significant $(\mathrm{p}<0.001)$.

Prothrombin Time:-

Table no 6a:- Prothrombin time abnormalities

\begin{tabular}{|l|l|l|l|l|}
\hline Patient group & No of cases & Range & Mean PT & \pm S.D \\
\hline Preeclamptic(A) & 68 & $0.84-1.03$ & 0.96 & 0.05 \\
\hline Eclamptic (B) & 32 & $0.82-1.37$ & 1.09 & 0.13 \\
\hline Control(C) & 40 & $0.77-1.05$ & 0.92 & 0.1 \\
\hline
\end{tabular}

Table no 6b:- Significance of difference from normal pregnant control.

\begin{tabular}{|l|l|l|l|l|}
\hline & SEM & Z value & P value & Significance \\
\hline A vs. C & $\mathbf{0 . 0 2}$ & $\mathbf{1 . 6 7}$ & $<\mathbf{0 . 1}$ & Insignificant \\
\hline B vs. C & $\mathbf{0 . 0 4}$ & $\mathbf{4 . 3 6}$ & $<\mathbf{0 . 0 0 1}$ & Highly significant \\
\hline
\end{tabular}

- Difference in mean value of P.T. of preeclamptic $(0.96 \pm 0.05$ S.D. $)$ and normal $(0.92 \pm 0.1$ S.D $)$ was statistically insignificant $(\mathrm{p}<0.1)$.

- Difference in mean value of P.T. of eclamptic (1.09 \pm 0.13 S.D.) and normal women (0.92 \pm 0.1 S.D) was statistically significant $(\mathrm{p}<0.001)$.

Thrombin Time:-

Table no 7a:- Thrombin time abnormalities

\begin{tabular}{|l|l|l|l|l|}
\hline Patient group & No of cases & Range & Mean TT & \pm S.D \\
\hline Preeclamptic(A) & 68 & $0.79-1.31$ & 0.99 & 0.13 \\
\hline Eclamptic (B) & 32 & $\mathbf{0 . 5 8 - 1 . 3 5}$ & 1.09 & 0.2 \\
\hline Control(C) & 40 & $\mathbf{0 . 7 1 - 0 . 9 8}$ & 0.86 & 0.09 \\
\hline
\end{tabular}

Table no 7b:- Significance of difference from normal pregnant control.

\begin{tabular}{|l|l|l|l|l|}
\hline & SEM & Z value & P value & Significance \\
\hline A vs. C & $\mathbf{0 . 0 3}$ & 4.33 & $<0.001$ & Highly significant \\
\hline B vs. C & $\mathbf{0 . 0 5}$ & 4.1 & $<0.001$ & Highly significant \\
\hline
\end{tabular}

- Difference in mean value of T.T. of preeclamptic $(0.99 \pm 0.13$ S.D. $)$ and normal (0.86 \pm 0.09 S.D) was statistically significant $(\mathrm{p}<0.001)$.

- Difference in mean value of T.T. of eclamptic (1.09 \pm 0.2 S.D.) and normal women (0.86 \pm 0.09 S.D) was statistically significant $(\mathrm{p}<0.001)$.

Activated Partial thromboplastin time (APTT):-

Table no 8a:- APTT abnormalities.

\begin{tabular}{|l|l|l|l|l|}
\hline Patient group & No of cases & Range (seconds) & Mean APTT & \pm S.D \\
\hline Preeclamptic(A) & 68 & $35.5-67.2$ & 49.96 & 8.72 \\
\hline Eclamptic (B) & 32 & $47.3-79.2$ & 59.26 & 11.65 \\
\hline Control(C) & 40 & $40.5-83.75$ & 55.59 & 12.19 \\
\hline
\end{tabular}

Table no 8b:- Significance of difference from normal pregnant control

\begin{tabular}{|l|l|l|l|l|}
\hline & SEM & Z value & P value & Significance \\
\hline A vs. C & 3.1 & $\mathbf{1 . 8}$ & $<0.1$ & Insignificant \\
\hline B vs. C & 3.99 & $\mathbf{0 . 9 2}$ & $<\mathbf{0 . 1}$ & Insignificant \\
\hline
\end{tabular}

- Difference in mean value of APTT of preeclamptic (49.96 \pm 8.72 S.D.) and normal (55.59 \pm 12.19 S.D) was statistically insignificant $(\mathrm{p}<0.1)$. 
- Difference in mean value of APTT of eclamptic (59.26 \pm 11.65 S.D.) and normal women (55.59 \pm 12.19 S.D) was statistically insignificant $(\mathrm{p}<0.1)$.

Plasma Fibrinogen:-

Table no 9a:- Plasma fibrinogen abnormalities

\begin{tabular}{|c|c|c|c|c|}
\hline Patient group & No of cases & Range (mg/dl) & $\begin{array}{ll}\text { Mean } & \text { plasma } \\
\text { fibrinogen }\end{array}$ & \pm S.D \\
\hline Preeclamptic(A) & 68 & $190.20-406.4$ & 350.23 & 58.53 \\
\hline Eclamptic (B) & 32 & $189.90-370$ & 227.5 & 57.45 \\
\hline Control(C) & 40 & 382.19-673.4 & 492.17 & 82.73 \\
\hline
\end{tabular}

Table no 8b:- Significance of difference from normal pregnant control.

\begin{tabular}{|l|l|l|l|l|}
\hline & SEM & Z value & P value & Significance \\
\hline A vs. C & 21 & 6.76 & $<0.001$ & Significant \\
\hline B vs. C & 23.42 & 11.3 & $<0.001$ & Significant \\
\hline
\end{tabular}

- Difference in mean value of Plasma fibrinogen of preeclamptic (350.23 \pm 58.53 S.D.) and normal (492.17 \pm 82.73 S.D) was statistically significant $(\mathrm{p}<0.001)$.

- Difference in mean value of plasma fibrinogen of eclamptic (227.50 \pm 57.45 S.D.) and normal women (492.17 \pm 82.73 S.D) was statistically significant $(\mathrm{p}<0.001)$.

Platelet Count:-

Table no 10a:- Platelet count abnormalities

\begin{tabular}{|l|l|l|l|l|}
\hline Patient group & No of cases & Range (lakhs/cmm) & Mean platelet count & \pm S.D \\
\hline Preeclamptic(A) & 68 & $0.9-3.4$ & 2 & 0.75 \\
\hline Eclamptic (B) & 32 & $0.78-2.8$ & 1.68 & 0.66 \\
\hline Control(C) & 40 & $2.10-3.5$ & 2.43 & 0.26 \\
\hline
\end{tabular}

Table no 10b:- Significance of difference from normal pregnant control.

\begin{tabular}{|l|l|l|l|l|}
\hline & SEM & Z value & P value & Significance \\
\hline A vs. C & $\mathbf{0 . 1 4 9}$ & $\mathbf{3}$ & $<\mathbf{0 . 0 0 1}$ & Significant \\
\hline B vs. C & $\mathbf{0 . 1 7 5}$ & $\mathbf{4}$ & $<\mathbf{0 . 0 0 1}$ & Significant \\
\hline
\end{tabular}

- Difference in mean value of platelet count of preeclamptic ( $2 \pm 0.75$ S.D. $)$ and normal $(2.43 \pm 0.26$ S.D $)$ was statistically significant $(\mathrm{p}<0.001)$.

- Difference in mean value of plasma fibrinogen of eclamptic (1.68 \pm 0.66 S.D.) and normal (2.43 \pm 0.26 S.D) was statistically significant $(\mathrm{p}<0.001)$.

\section{Summary:-}

The present work "coagulation profile as important markers in preeclampsia and eclampsia" was done retrospectively on 140 women of which 68 were preeclamptic, 32 were eclamptic and 40 were normal pregnant women in third trimester of pregnancy.

The summary of the work is as follows:

Bleeding time (B.T):-

- Difference in mean value of preeclamptic $(2.45 \pm 0.48$ S.D.) with that of normal (2.3 \pm 0.19 S.D. $)$ difference was insignificant $(\mathrm{p}<0.1)$

- Difference in mean value of B.T. of eclamptic (2.94 \pm 0.47 S.D. $)$ with that of normal $(2.3 \pm 0.19$ S.D. $)$ was significant $(\mathrm{p}<0.001)$

Clotting time (C.T.):-

- Difference in mean value of C.T. of preeclamptic (4.23 \pm 0.37 S.D.) and normal (4.2 \pm O.37 S.D) was statistically insignificant $(\mathrm{p}<0.1)$. 
- Difference in mean value of C.T. of eclamptic (5.19 \pm 0.38 S.D.) and normal women (4.2 \pm O.37 S.D) was statistically significant $(\mathrm{p}<0.001)$.

Prothrombin time (P.T.):-

- Difference in mean value of P.T. of preeclamptic (0.96 \pm 0.05 S.D.) and normal (0.92 \pm 0.1 S.D) was statistically insignificant $(\mathrm{p}<0.1)$.

- Difference in mean value of P.T. of eclamptic (1.09 \pm 0.13 S.D.) and normal women $(0.92 \pm 0.1$ S.D) was statistically significant $(\mathrm{p}<0.001)$.

\section{Thrombin time (T.T):-}

- Difference in mean value of T.T. of preeclamptic $(0.99 \pm 0.13$ S.D. $)$ and normal $(0.86 \pm 0.09$ S.D $)$ was statistically significant $(\mathrm{p}<0.001)$.

- Difference in mean value of T.T. of eclamptic (1.09 \pm 0.2 S.D.) and normal women $(0.86 \pm 0.09$ S.D) was statistically significant $(\mathrm{p}<0.001)$.

\section{Activated partial thromboplastin time (APTT):-}

- Difference in mean value of APTT of preeclamptic (49.96 \pm 8.72 S.D.) and normal (55.59 \pm 12.19 S.D) was statistically insignificant $(\mathrm{p}<0.1)$.

- Difference in mean value of APTT of eclamptic (59.26 \pm 11.65 S.D.) and normal women (55.59 \pm 12.19 S.D) was statistically insignificant $(\mathrm{p}<0.1)$.

\section{Plasma fibrinogen:-}

- Difference in mean value of Plasma fibrinogen of preeclamptic (350.23 \pm 58.53 S.D.) and normal (492.17 \pm 82.73 S.D) was statistically significant $(\mathrm{p}<0.001)$.

- Difference in mean value of plasma fibrinogen of eclamptic (227.50 \pm 57.45 S.D.) and normal women (492.17 \pm 82.73 S.D) was statistically significant $(\mathrm{p}<0.001)$.

\section{Platelet count:-}

- Difference in mean value of platelet count of preeclamptic ( $2 \pm 0.75$ S.D. $)$ and normal (2.43 \pm 0.26 S.D) was statistically significant $(\mathrm{p}<0.001)$.

- Difference in mean value of plasma fibrinogen of eclamptic (1.68 \pm 0.66 S.D.) and normal (2.43 \pm 0.26 S.D) was statistically significant $(\mathrm{p}<0.001)$.

\section{Conclusion:-}

Preeclampsia and eclampsia are an important cause of severe morbidity, long-term disability and death among both mothers and their babies.

However they can be avoided by assessment of coagulation profile early in pregnancy.

There was no significant difference in coagulation profile between patients of preeclampsia and eclampsia except more marked changes in the latter.

One can safely follow only platelet count on admission and subsequently do other coagulation parameters for those cases which have platelet count less than one lakh/cmm.

The clinical significance of thrombocytopenia in addition to obvious impairment of coagulation is that it reflects severity of pathological process. In general lower the platelet count, greater the maternal and foetal morbidity and mortality.

Thus by knowing the coagulation profile adequate management can be instituted i.e. fresh frozen plasma, compatible blood transfusion, induction of labour or caesarean section so that mothers and their babies can be saved from this fatal condition.

\section{Conflicts Of Interest:-}

The authors declare that there is no conflict of interests regarding the publication of this paper. 


\section{References:-}

1. Coagulation Parameters in Pre-eclamptic and Eclamptic Patients - A Comparative Study of 90 Cases Upam Kr. Sharma1 , Reena Kouli2, Ramesh Sonowal3, Projnan Saikia4

2. WHO recommendations for Prevention and treatment of pre-eclampsia and eclampsia

3. Ahmed y, van iddekinge B, Paul C, Sullivan MHF, Elder MG -Retrospective analysis of platelet numbers and volumes in normal pregnancy andin preeclampsia.Br J Obs Gyn,100:216-220;1993

4. Biland,B and Duckart F. Coagulation factors of the newborn and his mother

5. Weiner CP, Brandt J. Plasma antithrombin-III activity: an aid in the diagnosis of pre-eclampsia-eclampsia. Am J Obstet Gynecol. 1982;142:275-281.

6. Chauhan P, Rawat U, Bisht V, Purohit RC. "Comparison of Coagulation Profile in Pre-Eclamptic and Eclamptic Patients with Normotensive Pregnant Patients". Journal of Evolution of Medical and Dental Sciences. 2014;3:3208- 3215.

7. Vrunda JK, Shaila S. Lowered platelet count: A Prognostic Index in Pregnancy Induced Hypertension. J Obstet Gynecol Ind. 2004;54:235-6.

8. Sultana R, Karim SM, Atia F, Ferdousi S, Ahmed S. Platelet Count In Preeclampsia. J. Dhaka National Med. Coll. Hos. 2012; 18: 24-26

9. Coagulation Profiles in PIH -a) To Determine Coagulation Index to Distinguish Severe Preeclampsia from Normal Pregnancy b) To Assess the Correlation of Coagulation Parameters in Normal Pregnancy \& in Varying Grades of Preeclampsia Mirza Asif Baig. MD (Pathology) Former Assistant Professor BLDUs Shri B. M. Patil Medical College, Hospital \& Research Centre Bijapure, Karnataka, India

10. Brown MA, Lindheimer MD, de Swiet M, van Assche A, Moutquin JM. The classification and diagnosis of the hypertensive disorders of pregnancy: statement from the International Society for the Study of Hypertension in Pregnancy (ISSHP). Hypertens Pregnancy. 2001; 20: IX-XIV. [7] Cunningham F.G, Kenneth J. Leveno, StevenL. Bloom. Pregnancy induced hypertention. In: Kenneth J. Leveno, StevenL. William's Obstetrics, 23rd ed. New York ; 2010. p.706-56 